\title{
Genetic Diversity of Marine and Fresh Water Cyanobacteria from the Gujarat State of India
}

\author{
Nilkanth Faldu*, Shivani Patel, Nutan Prakash Vishwakarma, Anil Kumar Singh, \\ Khushbu Patel, Neepa Pandhi \\ Department of Biotechnology, Shree M. \& N. Virani Science College, Gujarat, India \\ Email: prabhumay@vsc.edu.in
}

Received 5 October 2014; revised 6 November 2014; accepted 1 December 2014

Copyright (C) 2014 by authors and Scientific Research Publishing Inc.

This work is licensed under the Creative Commons Attribution International License (CC BY). http://creativecommons.org/licenses/by/4.0/

c) (i) Open Access

\begin{abstract}
Cyanobacteria from habitats within Gujarat have been poorly studied with regard to their diversity. In the present investigation eight morphologically distinct cyanobacterial isolates were obtained and characterized from the fresh water and marine habitats. Identification was performed based on morphological features and on 16S rDNA sequences analysis. A phylogenetic tree based on 16S rDNA sequence of cyanobacterial isolates was prepared. Phylogenetic analysis clustered the eight morphologically distinct isolates into two distinct groups thus highlighting the importance of both morphological and genetic methods in studying cyanobacterial diversity.
\end{abstract}

\section{Keywords}

Cyanobacteria, 16S rDNA, Phylogenetic Analysis, Cyanobacterial Diversity

\section{Introduction}

Cyanobacteria were the first prokaryotic organisms believed to have evolved on earth approximately 3.8 billion years ago. They constitute one of the major gram negative bacterial phyla and occupy the diverse range of habitats inhabiting most of the Earth's environment. They display considerable morphological diversity ranging from unicellular to colonial and filamentous forms. Cyanobacteria are capable of photo-autotrophic growth; perform oxygenic photosynthesis similar to those of eukaryotic algae and plants. They also have the unique ability to fix atmospheric nitrogen [1] [2].

Cyanobacteria can be classified on the basis of morphology, cellular differentiation, biochemical, physiologi$\mathrm{cal}$ and genetic criteria. The taxonomy of cyanobacteria until now has been based mainly on their morphology and according to it they are classified into five orders: Chroococcales (I), Pleurocapsales (II), Oscillatoriales (III),

\footnotetext{
"Corresponding author.
}

How to cite this paper: Faldu, N., Patel, S., Vishwakarma, N.P., Singh, A.K., Patel, K. and Pandhi, N. (2014) Genetic Diversity of Marine and Fresh Water Cyanobacteria from the Gujarat State of India. Advances in Bioscience and Biotechnology, 5, 1061-1066. http://dx.doi.org/10.4236/abb.2014.514121 
Nostocales (IV) and Stigonematales (V). However, the morphology and other phenotypic characteristics of cyanobacteria can be dramatically influenced by environmental factors and stage of development [3] [4]. Thus, classifications based on phenotypic characteristics do not represent natural grouping when analyzed based on genetic data.

DNA base composition is important genetic character used to study the taxonomy of cyanobacteria. Analysis of the DNA base composition (Mol \% G + C) is one of the few molecular characters that have been determined for almost 200 cyanobacterial strains. Comparative analysis of 16S ribosomal RNA sequence has been used for identification and construction of cyanobacterial phylogeny [5].

Gujarat state of India is rich in both fresh water and marine ecosystems. In the present study we have isolated eight cyanobacterial strains from freshwater and marine ecosystems and tried to explore their diversity using morphology and 16S rRNA sequence analysis.

\section{Material and Methods}

\subsection{Sample Collection}

Water samples were collected from five different regions of the Gujarat state namely Rajkot, Bhuj, Positara, Gadhada, Okha, Mithapur, which include both fresh and marine habitats and were stored in a growth chamber at $25^{\circ} \mathrm{C}$ with under 8 hours $/ 16$ hours dark/light photoperiod. For morphological studies, the strains were cultivated in BG11 medium [6].

Pure cultures of cyanobacteria were obtained by three techniques viz. enrichment, serial dilution and direct streak plate method. In the serial dilution method, the inoculum was prepared by mixing the samples with sterilized BG11 medium and then serial dilutions were made in test tubes containing same medium. The tubes were incubated at $25^{\circ} \mathrm{C}$ under 8 hours/16 hours dark/light photoperiod. After growth the culture was streaked on BG11 agar plates to obtain unialgal cultures. In the streak plate method, the crude samples were directly streaked on BG11 agar plates. The plates were incubated at $25^{\circ} \mathrm{C}$ under 8 hours/16 hours dark/light photoperiod. Through successive streaking or transferring from one agar plate to another, unialgal cultures were obtained. Unialgal stocks were maintained in $100 \mathrm{ml}$ liquid medium as well as on agar slants and stored at $25^{\circ} \mathrm{C}$ under low light intensity.

Axenic culture of cyanobacteria was obtained by treating the cells with standard antibiotic solution (Streptomycin, Nalidixic acid, Ampicillin and Cycloheximide). $400 \mu \mathrm{L}$ of sterile BG11 medium was added along with $400 \mu \mathrm{L}$ of sterile antibiotic solution in both solid and liquid media to give a final antibiotic concentration of 50 $\mu \mathrm{g} / \mathrm{ml}$. The culture was then incubated at room temperature under darkness. The morphology of cells and filaments was studied using an Olympus $45 \times$ light microscope with a digital camera.

\subsection{DNA Extraction, PCRs and Sequencing}

Purelink Plant DNA extraction kit (Invitrogen, USA) was used to obtain high quality genomic DNA samples from cyanobacterial isolates, according to the manufacturer's protocol. Electrophoresis was done in $0.8 \%$ agarose gel at $5 \mathrm{~V} / \mathrm{cm}$ for $30 \mathrm{~min}$. Quantity of the genomic DNA was estimated spectrophotometrically by measuring absorbance at $280 \mathrm{~nm}$ while the quality was determined by taking ratio of absorbance at 260 and $280 \mathrm{~nm}$ in a UV 1800 Shimadzu UV Vis Spectrophometer.

\subsection{PCR Amplifications}

In order to the get the sequence of $16 \mathrm{~S}$ rDNA from cyanobacterial isolates, the 16s rRNA gene was amplified using two sets of oligonucleotide primers in separate PCR reactions [7]. The sequence of the primer and the approximate length of DNA amplified by them are given in Table 1.

\begin{tabular}{|c|c|c|}
\hline Set & Primer sequence & Length of PCR amplicon \\
\hline 1 & $\begin{array}{l}\text { CYA106F-5'CGGACGGGTGAGTAACGCGTGA3' } \\
\text { CYA781R-5’GACTACTGGGGTATCTAATCCCATT3', }\end{array}$ & 675 \\
\hline 2 & $\begin{array}{l}\text { CYA106F-5'CGGACGGGTGAGTAACGCGTGA3' } \\
\text { CYAN1281R-5'GCAATTACTAGCGATTCCTCC3' }\end{array}$ & 1175 \\
\hline
\end{tabular}


PCR were performed by GeneAmp PCR system 9700. The PCR reaction mixture ( $20 \mu \mathrm{L}$ total volume) consisted of $100 \mathrm{ng}$ genomic DNA, $1.5 \mathrm{mM} \mathrm{MgCl}, 10 \mathrm{mM}$ of each dNTP, $1 \mathrm{xTaq}$ buffer, $10 \mu \mathrm{M}$ of each primer and 1 unit of Taq polymerase. Samples were subjected to the following thermal profile: $3 \mathrm{~min}$ of denaturing at $94^{\circ} \mathrm{C}$ and 30 cycles of three steps: $30 \mathrm{sec}$ of denaturing at $94^{\circ} \mathrm{C}, 30 \mathrm{sec}$ of annealing at $58^{\circ} \mathrm{C}$, and $1 \mathrm{~min}$ of elongation at $72^{\circ} \mathrm{C}$ followed by final extension of 10 minutes at $72^{\circ} \mathrm{C}$. A digital gel image of the gel was obtained in Gel Doc XR system (Bio-Rad) using QUANTITY ONE ${ }^{\circledR}$ 1-D V 4.6.7 analysis software.

\subsection{Sequencing}

After purification [PCR purification kit (Genei, Bangalore)] the PCR amplicons were directly sequenced at 1st BASE DNA sequencing Services, Malaysia. The sequence obtained using both set of primers were checked for overlaps and a final sequence of 1175 base pair was obtained. The sequences obtained were submitted to NCBI (KC140132 - KC140134 and KC248207 - KC248211).

\subsection{Phylogenetic Analysis}

DNA sequence data was analyzed by BLAST. Multiple sequence alignments were generated using the CLUSTALW program [8]. Phylogenetic distance trees were inferred by Neighbour-Joining analyses [9], using MEGA5.10 [10]. Confidence in topologies was assessed using bootstrapping (1000 replicates).

\section{Result}

\subsection{Morphological Characteristics of Isolated Cyanobacteria}

On microscopic observation of samples we distinguished eight different cyanobacterial morphotypes. Figure 1 shows the morphological diversity among the isolates.

\subsection{Amplification of $16 S$ rRNA Gene by PCR}

The 16S rRNA gene was amplified using hot start PCR with two set of primers, CYA106F and CYA781R; CYA106F and CYA1281R. A PCR product of 675 bp was obtained using the first set and an amplification product 1175 bp was obtained using the second set of primer (Figure 2). The sequence obtained using both primers were aligned to get the complete sequence of $1175 \mathrm{bp}$ as sequencing gave a read only up to $700 \mathrm{bp}$. The complete sequences of 1175 bp were submitted to NCBI.

\subsection{Phylogenetic Tree}

A phylogenetic tree based on 16S rRNA sequences was constructed using MEGA 5.10 software (Figure 3). The
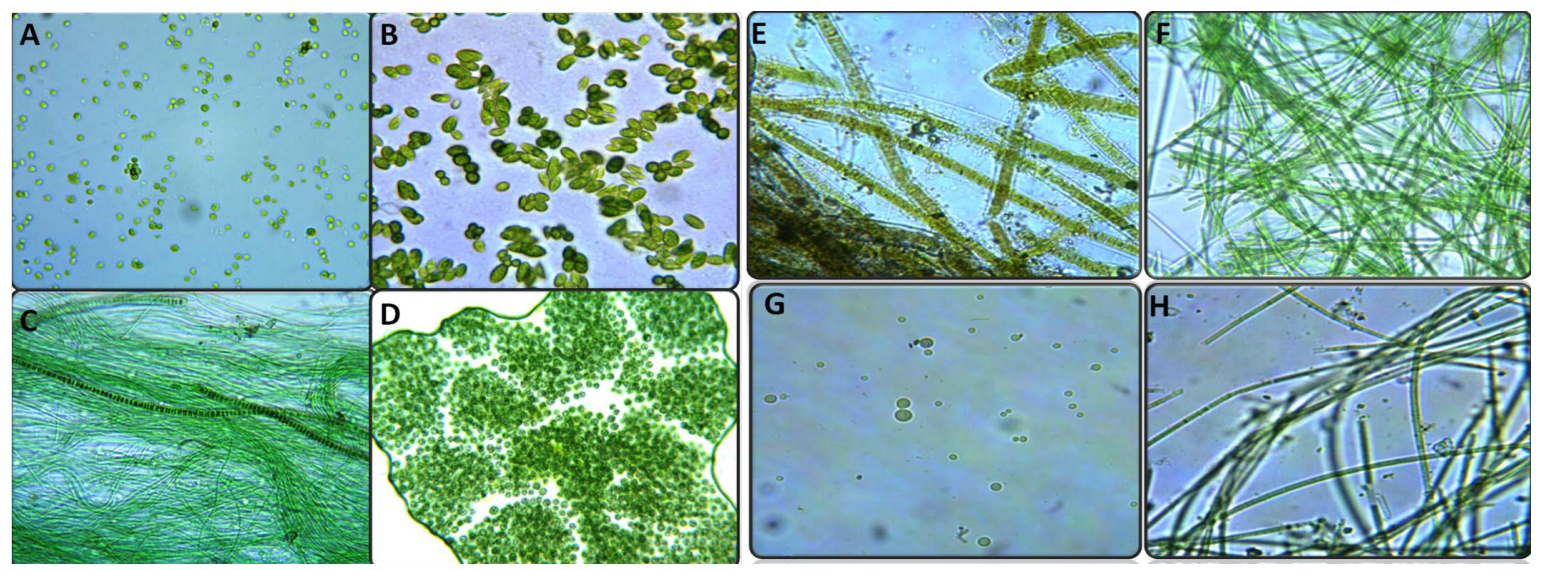

Figure 1. Light micrograph illustrating the diversity of Cyanobacterial morphotypes isolated from the Gujarat state of India. (A) Cyanobacterium sp. PBJ1 KC248207.1; (B) Cyanobacterium sp. PBJ2 KC248208.1; (C) Cyanobacterium sp. PRJT KC140132.1; (D) Cyanobacterium sp. PSGH KC248209.1; (E) Cyanobacterium sp. POKH1 KC140133.1; (F) Cyanobacterium sp. POKH2 KC248210.1; (G) Cyanobacterium sp. PMTP KC248211.1; (H) Cyanobacterium sp. PPST KC140134.1. 


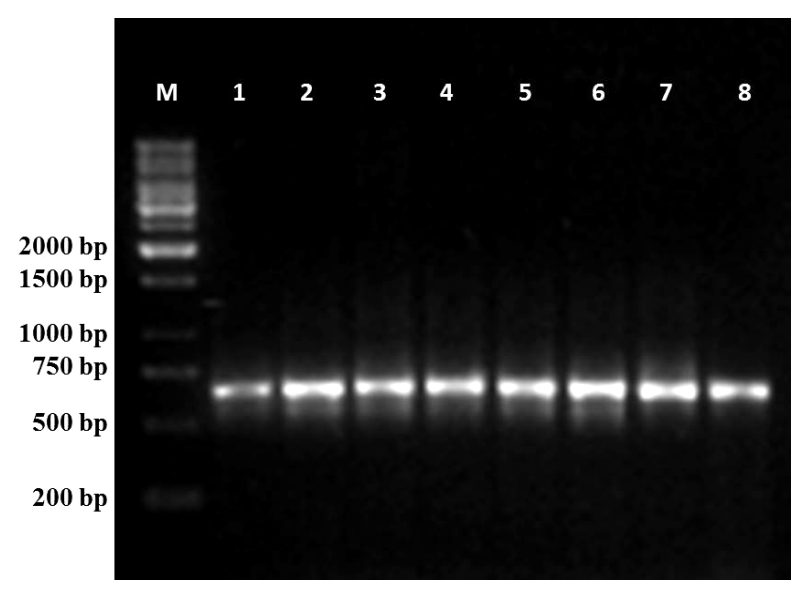

(A)

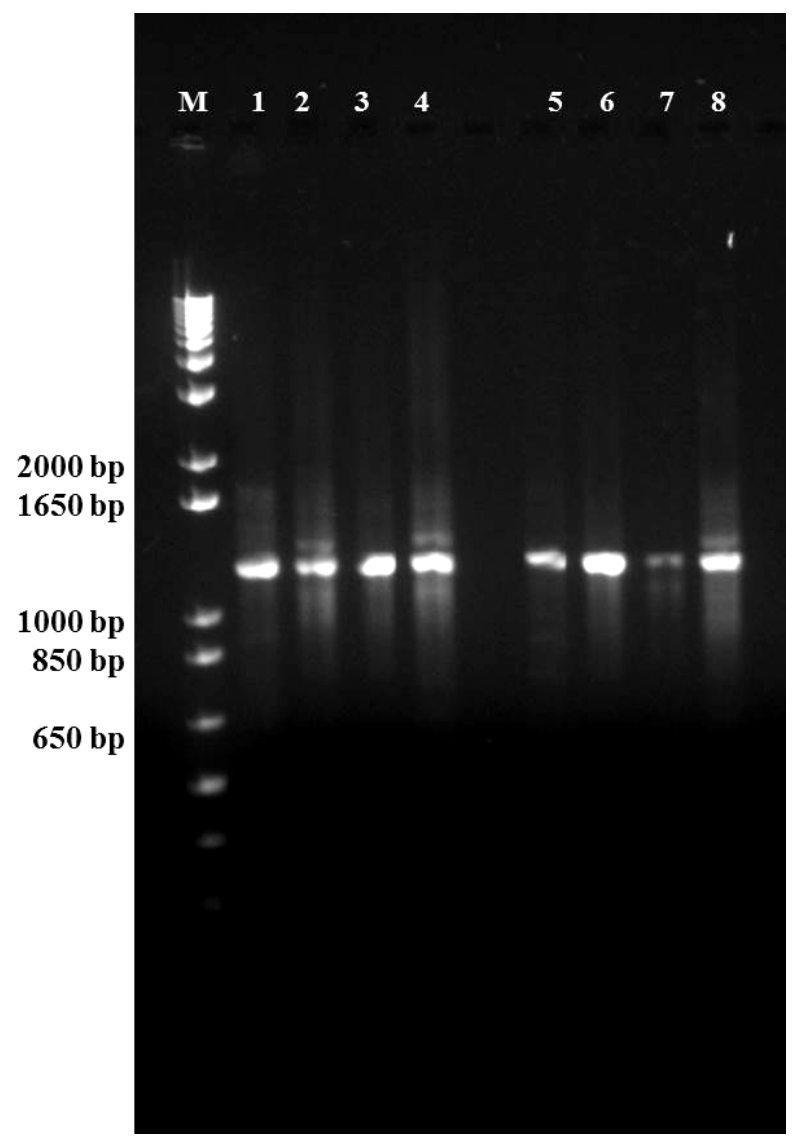

(B)

Figure 2. PCR amplicons of $16 \mathrm{~S}$ rDNA gene in $1.0 \%(\mathrm{w} / \mathrm{v})$ agarose gel. (A) PCR amplification using primers CYA106F and CYA781R; (B) PCR amplification using primers CYA106F and CYA1281R (M, Marker; 1, PBJ1; 2, PBJ2; 3, PRJT; 4, PSGH; 5, POKH1; 6, POKH2; 7, PMTP; 8, PPST).

isolates grouped into two clusters, the first cluster, supported by $100 \%$ bootstrap value, included isolates Cyanobacterium sp. POKH1, Cyanobacterium sp. PSGH, Cyanobacterium sp. PBJ1, and Cyanobacterium sp. PBJ2 while the other cluster which was not supported by a sufficient bootstrap value included Cyanobacterium sp. PRJT, Cyanobacterium sp. POKH2, Cyanobacterium sp. PPST and Cyanobacterium sp. MTP. 


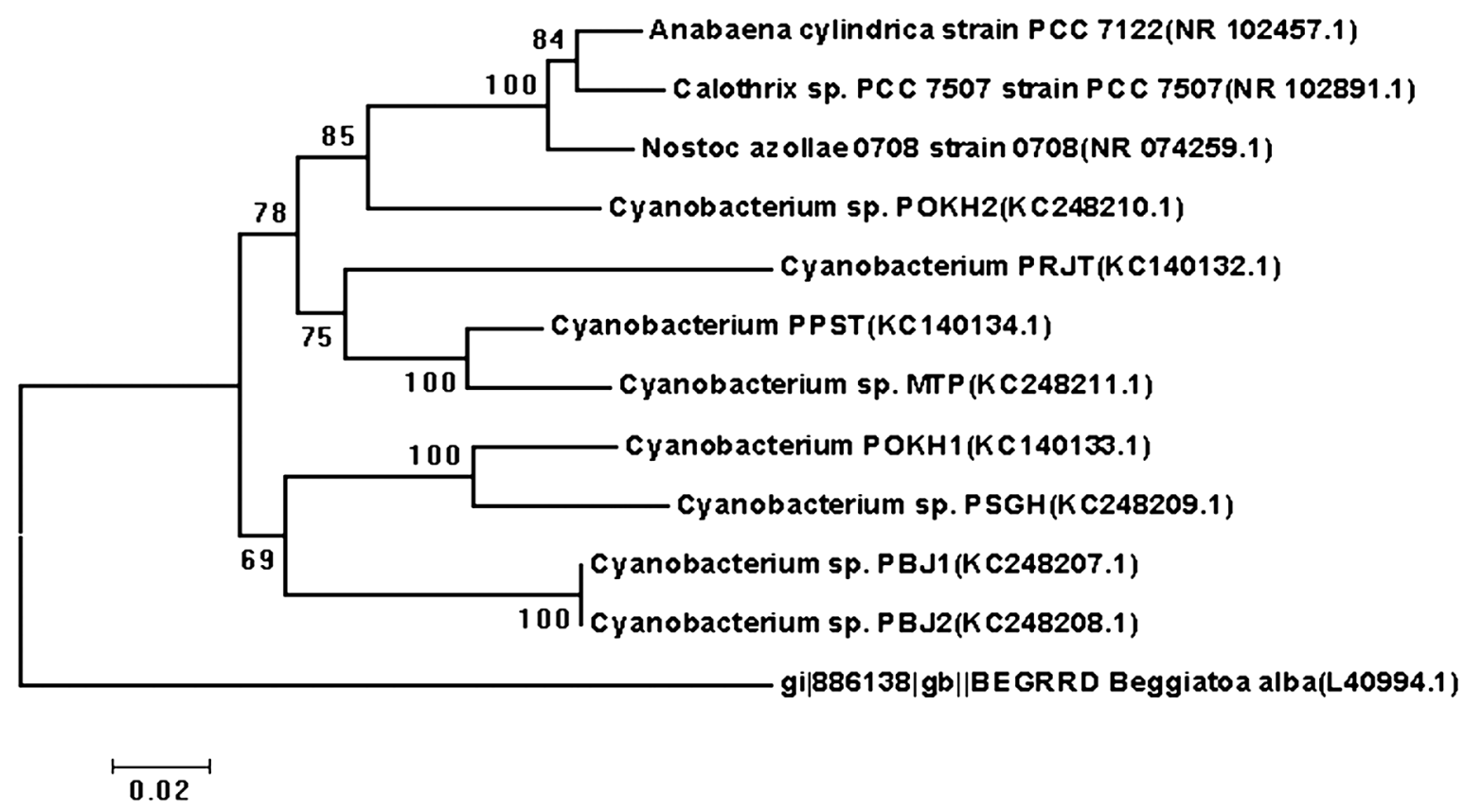

Figure 3. Phylogenetic tree based on an alignment containing the partial 16S rRNA gene sequences from 8 cyanobacteria constructed by neighbour-joining with Beggiatoa alba as outgroup.

\section{Discussion}

Pure cultures of cyanobacteria are essential for studying various aspects of their biology. Gujarat state of India has one of the largest coastlines but still there are very few reports on isolation, characterization and diversity of cyanobacteria from these habitats. Since isolation and culturing of all forms of cyanobacteria are difficult, we are able to isolate only eight morphologically distinct cyanobacterial isolates from water samples collected from different regions of Gujarat. The general inability of cyanobacterial species to grow as unialgal culture has been noted in the literature and has been attributed to the fact that laboratory environment is quite different compared to natural habitats [11]. Also, the variety of biotic interactions that exists among species may be critically important for the survival for cyanobacterial species. The 16S rRNA gene sequence analysis grouped these eight morphologically distinct isolates into two distinct clusters, highlighting the importance of both morphological and genetic methods in studying cyanobacterial diversity. The cyanobacteria has been reported to exhibit pronounced polymorphism with changing environmental conditions, and thus studying diversity just based on morphological characteristics is not sufficient [12]. Garcia-Pichel et al. (1998) also demonstrated that morphology is not a phylogenetically reliable character for the taxonomy of cyanobacteria and it has to be substantiated with physiological and genetic characteristics [13]. 16S rRNA gene analyses have been used to study the diversity of cyanobacteria. Analysis of diversity based on comparison 16S rRNA gene sequences is a reliable way of studying cyanobacterial diversity.

Our work is a preliminary report on isolation, characterization and diversity of cyanobacterial isolates from Gujarat state of India.

\section{Conflicts of Interest Statement}

The experiments comply with the current laws of the countries in which the experiments were performed. The authors declare no conflict of interest.

\section{Acknowledgements}

Author wishes to acknowledge Sarvoday Kelavani Samaj, Rajkot and UGC for financial assistance under scheme of college teachers for Minor Research Project to Mr. N. J. Faldu [(F. No. 47-1316/10 (WRO)]. The authors also grateful to Mrs. Sheetal Tank, Librarian, AITS and K.D. Ladva, Head, Department of Chemistry for 
their kind support and guidance.

\section{References}

[1] Stanier, R.Y. (1979) Generic Assignments: Strain Histories and Properties of Pure Cultures of Cyanobacteria. Microbiology, 110, 1-61.

[2] Görl, M., Sauer, J., Baier, T. and Forchhammer, K. (1998) Nitrogen-Starvation-Induced Chlorosis in Synechococcus PCC 7942: Adaptation to Long-Term Survival. Microbiology, 144, 2449-2458. http://dx.doi.org/10.1099/00221287-144-9-2449

[3] Suda, S., Watanabe, M.M., Otsuka, S., Mahakahant, A., Yongmanitchai, W., Nopartnaraporn, N., et al. (2002) Taxonomic Revision of Water-Bloom-Forming Species of Oscillatorioid Cyanobacteria. International Journal of Systematic and Evolutionary Microbiology, 52, 1577-1595. http://dx.doi.org/10.1099/ijs.0.01834-0

[4] Rajaniemi, P., Hrouzek, P., Kastovská, K., Willame, R., Rantala, A., Hoffmann, L., et al. (2005) Phylogenetic and Morphological Evaluation of the Genera Anabaena, Aphanizomenon, Trichormus and Nostoc (Nostocales, Cyanobacteria). International Journal of Systematic and Evolutionary Microbiology, 55, 11-26. http://dx.doi.org/10.1099/ijs.0.63276-0

[5] Giovannoni, S.J., Turner, S., Olsen, G.J., Barns, S., Lane, D.J. and Pace, N.R. (1988) Evolutionary Relationships among Evolutionary Relationships among Cyanobacteria and Green Chloroplasts. Journal of Bacteriology, 170, 35843592.

[6] Stanier, R.Y., Kunisawa, R. and Mandel, M. (1971) Purification and Properties of Unicellular Blue-Green Algae (Order Chroococcales). Bacteriological Reviews, 35, 171-205.

[7] Garcia-pichel, F., Nu, U. and Muyzer, G. (1997) PCR Primers to Amplify 16S rRNA Genes from Cyanobacteria. Applied and Environmental Microbiology, 63, 3327-3332.

[8] Thompson, J.D., Higgins, D.G. and Gibson, T.J. (1994) CLUSTAL W: Improving the Sensitivity of Progressive Multiple Sequence Alignment through Sequence Weighting, Position-Specific Gap Penalties and Weight Matrix Choice. Nucleic Acids Research, 22, 4673-4680. http://dx.doi.org/10.1093/nar/22.22.4673

[9] Saitou, N. and Nei, M. (1987) The Neighbor-Joining Method: A New Method for Reconstructing Phylogenetic Trees. Molecular Biology and Evolution, 4, 406-425.

[10] Tamura, K., Peterson, D., Peterson, N., Stecher, G., Nei, M. and Kumar, S. (2011) MEGA5: Molecular Evolutionary Genetics Analysis Using Maximum Likelihood, Evolutionary Distance, and Maximum Parsimony Methods. Molecular Biology and Evolution, 28, 2731-2739. http://dx.doi.org/10.1093/molbev/msr121

[11] Bano, A. and Siddiqui, P.J.A. (2004) Characterization of Five Marine Cyanobacterial Species with Respect to Their $\mathrm{pH}$ and Salinity Requirements. Pakistan Journal of Botany, 36, 133-143.

[12] Dor, I. and Ehruch, A. (1987) The Effect of Salinity and Temperature Gradients on the Distribution of Littoral Microalgae in Experimental Solar Ponds, Dead Sea Area, Israel. Marine Ecology, 8, 193-205. http://dx.doi.org/10.1111/j.1439-0485.1987.tb00183.x

[13] Garcia-Pichel, F. and López-cortés, A. (2001) Phylogenetic and Morphological Diversity of Cyanobacteria in Soil Desert Crusts from the Colorado Plateau. Applied and Environmental Microbiology, 67, 1902-1910. http://dx.doi.org/10.1128/AEM.67.4.1902-1910.2001 
Scientific Research Publishing (SCIRP) is one of the largest Open Access journal publishers. It is currently publishing more than 200 open access, online, peer-reviewed journals covering a wide range of academic disciplines. SCIRP serves the worldwide academic communities and contributes to the progress and application of science with its publication.

Other selected journals from SCIRP are listed as below. Submit your manuscript to us via either submit@scirp.org or Online Submission Portal.
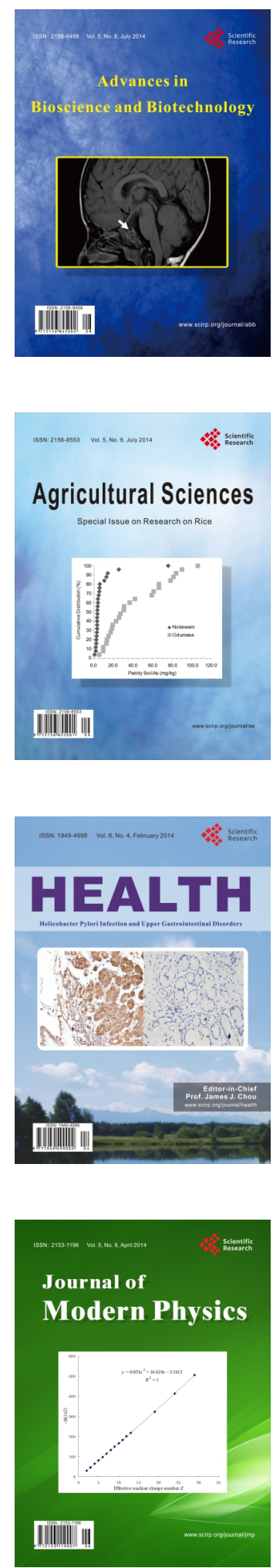
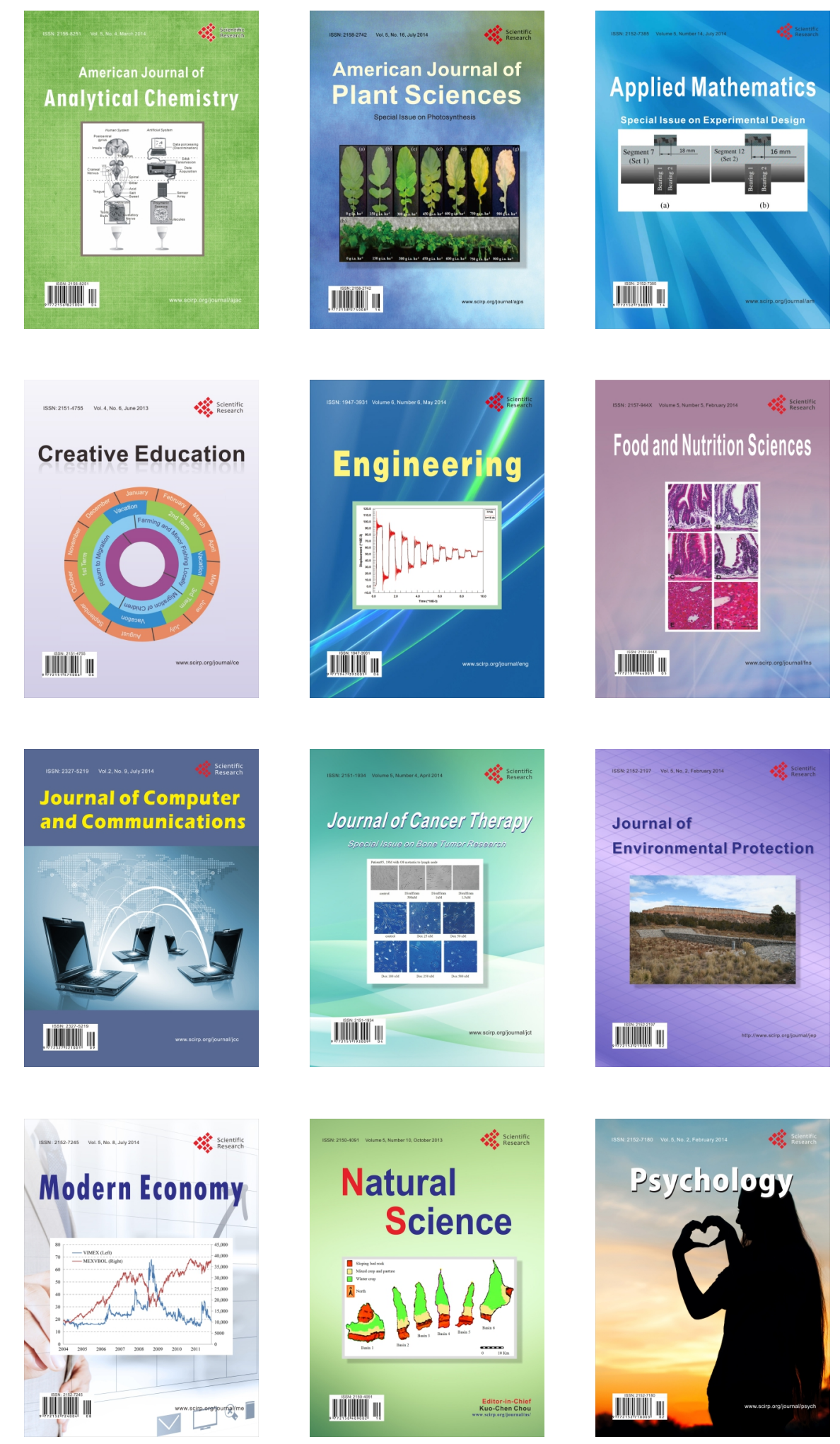